\title{
Note on the clutch size and egg morphometry of Oligodon albocinctus and Hebius xenura (Reptilia: Serpentes: Colubridae)
}

\author{
Samuel Lalronunga ${ }^{1,2 *}$, Lalkhawngaiha Sailo ${ }^{2}, V^{2}$ anlalchhuanga ${ }^{3}$, H. Lalmuanpuia ${ }^{4}$, \\ Isaac Zosangliana ${ }^{5}$, Ngurthanmawia $^{6}$, Nicky Malsawmtluanga $^{7}$, Malsawmdawngliana $^{2}$, \\ J. Ramdinmawia ${ }^{8}$, Lalmuanpuia ${ }^{2}$, Zodinliana Fanai ${ }^{2}$, C. Lalremtluanga ${ }^{9}$ \\ IDepartment of Zoology, Pachhunga University College, Aizawl 7960oI, Mizoram, India. \\ ${ }^{2}$ Biodiversity and Nature Conservation Network, Mission Veng, Aizawl 7960oI, Mizoram, India \\ ${ }^{3}$ Ramthar North, ${ }^{5}$ Electric Veng, ${ }^{6}$ Thakthing Veng, ${ }^{7}$ Chhinga Veng, Aizawl 796ooI, Mizoram, India \\ ${ }^{4}$ Arpu Veng, Sihphir 796036, Mizoram, India \\ ${ }^{8}$ Ramhlun Vengthar, ${ }^{9}$ Mission Vengthlang, Aizawl 796or2, Mizoram, India
}

We report the clutch size, egg morphometry and timing of oviposition in two snakes, Oligodon albocinctus and Hebius xenura based on specimens from Mizoram, northeast India.

Key words: clutch size, breeding, Mizoram, oviposition.

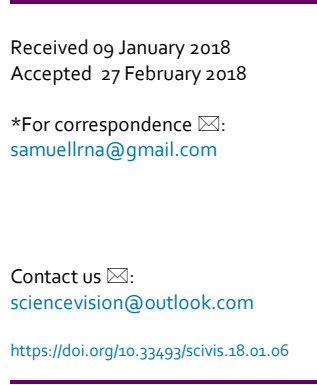

Received og January 2018 Accepted 27 February 2018

*For correspondence $\bowtie$ : samuellrna@gmail.com
The light-barred kukri snake, Oligodon albocinctus (Cantor, 1839) is distributed in eastern and north-eastern India, Bangladesh, Bhutan, Nepal and Myanmar. ${ }^{1}$ Oligodon albocinctus is characterized by having brownish-red dorsum with black-edged white, yellow or fawn (19-27 on body and 4-8 on tail) cross-bars; V-shaped yellow or cream mark on forehead. Even though the snake is common in its distribution range, only single report exist on the clutch size.? Wall's keelback, Hebius xenura (Wall, 1907) is a rare snake distributed from Meghalaya, $\mathrm{Na}$ galand and Mizoram in northeast India to Sagaing and Rakhine in Myanmar. ${ }^{1}$ The species is characterized by having olive-brown to nearly black dorsum with paired series of reddishorange, pale brown, yellow or white spots on flanks; and markedly differs from all other species of the genus from this region in having an entire sub-caudal scales. The species is known to lay eggs, ${ }^{3}$ but apart from this, little is known about its breeding biology and clutch size. ${ }^{1}$ Herein we report the clutch size, egg morphometry and timing of oviposition in $O$. albocinctus and $H$. xenura specimens from Mizoram, northeast India.

On 20 September 2017, we received an adult female O. albocinctus (410 $\mathrm{mm}$ SVL) that had been collected on 15 September 2017 from a residential area in Lunglei, Mizoram. On 21 September 


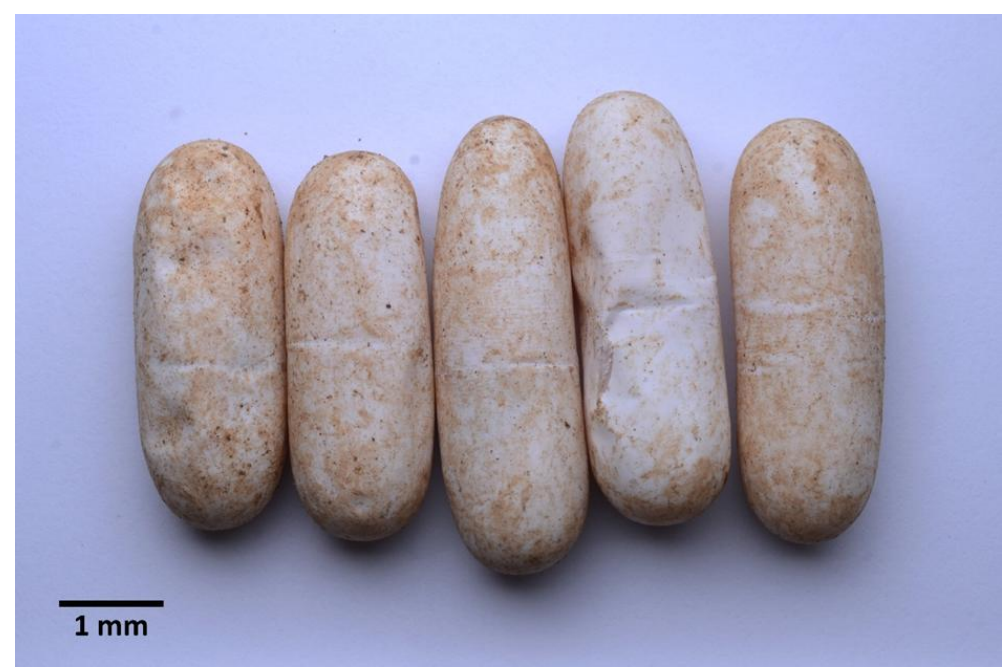

Figure 1 | Eggs of Oligodon albocinctus from Mizoram.

2017 at $\mathrm{ca} .0930 \mathrm{~h}$ we found a clutch containing 5 eggs in the terrarium. After the length and width of the eggs were measured, they were removed from the terrarium for incubation and the snake was released in the wild. The eggs were white, nonadherent, elliptical and elongated, about three times longer than broad (Fig. 1). The height of the eggs ranged from $39.1-45.8 \mathrm{~mm}$ (mean $=42.0 \mathrm{~mm}$ ) and the diameter ranged from $14.0-14.9 \mathrm{~mm}$ (mean $=14.5 \mathrm{~mm}$ ). The reported clutch size of $O$. albocinctus is 3 , which is based on a dead gravid specimen examined by Wall ${ }^{2}$, and this record is followed by subsequent authors. ${ }^{1,3-5}$ The present record on the clutch size of o. albocinctus from Mizoram is higher than previously recorded.

On 9 August 2017, a female H. xenura (570mm SVL) was collected from a residential area in Aizawl, Mizoram and was kept in a terrarium prior to its release in the wild. Upon closer examination, it was found to be gravid. Five days post capture, it deposited 2 eggs. After the length and width of the eggs were measured, they were removed from the terrarium for incubation and the snake was released in the wild there after. The eggs were white, nonadherent, elliptical and elongated, about two times longer than broad. The height of the eggs ranged from 26.9-29.2 $\mathrm{mm}$ (mean $=28.5 \mathrm{~mm}$ ) and the diameter ranged from $12.3-12.6 \mathrm{~mm}$ (mean $=12.5 \mathrm{~mm}$ ). The present observation adds valuable information on the natural history of the species.

\section{Acknowledgement}

We thank K. Lalhmangaiha and H. Vanlalmalsawma for bringing the specimens to our attention. Research and collection of specimens was conducted under permit number A.38011/5/2011-CWLW/338 issued by Chief Wildlife Warden, Environment, Forest and Climate Change Department, Government of Mizoram, India.

\section{References}

I. Das, I. (20I2) Snakes of South-East Asia. John Beaufoy Publishing, Oxford, England.

2. Wall, F. (1923). A review of the Indian species of the genus Oligodon suppressing the genus Simotes (Ophidia). Records of the Indian Museum 25, 305-334.

3. Whitaker, R. \& Captain, A. (2008). Snakes of India, The Field Guide. Draco Books, Chennai, India. 385 pp.

4. Ahmed, M.F., Das, A. \& Dutta S.K. (2009) Amphibians and Reptiles of Northeast India - A Photographic Guide. Aaranyak, Guwahati, India.

5. Lalremsanga, H.T. \& Lalronunga, S. (2017). Mizoram Rul Chanchin. BIOCONE and MISTIC, Aizawl, India. 